\title{
Electro-thermal impedance spectroscopy applied to an open- cathode polymer electrolyte fuel cell
}

Erik Engebretsen ${ }^{1}$, James B. Robinson ${ }^{1}$, Oluwamayowa Obeisun ${ }^{1}$, Tom Mason ${ }^{1}$, Donal Finegan $^{1}$, Gareth Hinds ${ }^{2}$, Paul R. Shearing ${ }^{1}$, Daniel J. L. Brett ${ }^{1 *}$

${ }^{1}$ Electrochemical Innovation Lab, Department of Chemical Engineering, UCL, London, UK, WC1E 7JE

${ }^{2}$ National Physical Laboratory, Hampton Road, Teddington, Middlesex, UK, TW11 OLW

* Author to whom correspondence should be addressed

Tel.: +44(0)20 76793310

Web: www.ucl.ac.uk/eil

Email: d.brett@ucl.ac.uk

\begin{abstract}
The development of in-situ diagnostic techniques is critical to ensure safe and effective operation of polymer electrolyte fuel cell systems. Infrared thermal imaging is an established technique which has been extensively applied to fuel cells; however, the technique is limited to measuring surface temperatures and is prone to errors arising from emissivity variations and reflections. Here we demonstrate that electro-thermal impedance spectroscopy can be applied to enhance infrared thermal imaging and mitigate its limitations. An open-cathode polymer electrolyte fuel cell is used as a case study. The technique operates by imposing a periodic electrical stimulus to the fuel cell and measuring the consequent surface temperature
\end{abstract}


response (phase and amplitude). In this way, the location of heat generation from within the component can be determined and the thermal conduction properties of the materials and structure between the point of heat generation and the point of measurement can be determined. By selectively 'locking-in' to a suitable modulation frequency, spatially resolved images of the relative amplitude between the current stimulus and temperature can be generated that provide complementary information to conventional temporal domain thermograms.

\section{Keywords}

Electro-thermal impedance spectroscopy; lock-in thermography; transfer function analysis; polymer electrolyte fuel cell; thermal imaging; electro-thermography.

\section{Highlights}

- Electro-thermal impedance spectroscopy applied to a PEFC

- ETIS corrects for emissivity variation and reflection

- Electro-thermo-ampligrams identify areas of heat generation

- Current-related features decoupled from temperature distribution

\section{Introduction}

Polymer electrolyte fuel cells (PEFCs) have shown great promise as power sources in a range of applications due to their high efficiency and low temperature operation $[1,2]$. However, the widespread adoption of PEFCs has been hampered by, amongst other things, a lack of operationally relevant thermal characterisation and in-situ diagnostic techniques. 
Electrochemical Impedance Spectroscopy (EIS) is a powerful technique used to deconvolute the various loss mechanisms in electrochemical systems and devices [3-5]. A small voltage (or current) perturbation is applied over a range of frequencies, while measuring the resultant current (or voltage) response. Transfer function analysis allows processes occurring with different time constants to be identified, such as kinetic, Ohmic and mass transfer impedances in fuel cells [6], which provides valuable information regarding fuel cell performance. This principle can be modified in order to derive new diagnostic techniques - for instance electrothermal impedance spectroscopy (ETIS).

ETIS is a technique that applies a similar transfer function analysis to EIS; in this instance, a small current (or voltage) perturbation is related to modulation of heat generation, and consequently the measured temperature. The relative amplitude and phase shift between the periodic current stimulus and the temperature response are frequency dependent and can yield information on the electro-thermal properties of electrochemical devices [7-9]. For example, Schmidt et al. [7] applied the technique to a Li-ion pouch cell, measuring the surface temperature at a single point with a thermocouple. The relative amplitude of the thermal response to the current perturbation is analogous to the 'thermal impedance' of the system; a higher thermal impedance through a material results in a lower temperature at the surface of the material. The phase shift between the perturbation and response is analogous to 'thermal capacitance'; the finite thermal diffusivity of a material means that there is a time lag between perturbation and response.

Lock-in thermography is an established technique that typically uses a thermal stimulus (e.g. a heat gun or IR lamp) imposed on a sample, with the resultant temperature modulation measured to give spatially resolved information about heat transfer in a system (identification 
of cracks in components, for example) $[10,11]$. Reflected artefacts and variations in emissivity can be rejected, thereby improving image fidelity. However, other forms of modulation stimulus can be used that result in heat generation (e.g. mechanical stress, ultrasound, electrical current) [11]. Robinson et al. [12] applied lock-in thermography to a Li-ion pouch cell with a periodic current stimulus, highlighting the ability of the technique to identify sub-surface defects; in this instance, gas pockets formed during cell aging. The technique has also been applied to silicon materials for solar applications to identify regions containing recombination-active grain boundaries [13]; in photovoltaic modules to determine shunt values $[14,15]$, and in semiconductors to identify cracks [16].

The power and efficacy of lock-in thermography is governed by the ability to interpret the images. This necessitates appreciation of the factors that lead to phase and amplitude shifts, $a$ priori knowledge of the physical structure and materials of the device, and intelligent selection of the modulation frequency. Where the internal structure of devices can be determined using techniques such as X-ray computed tomography, the application of ETIS can provide insight into selection of modulation frequency and interpretation of images [17].

Here, for the first time, ETIS is applied to a PEFC to determine the frequency, polarisation, and spatially-dependent behaviour of the system and to inform interpretation of lock-in images (electro-thermo-ampligrams). The open-cathode configuration allows for direct visualisation of the gas diffusion layer (GDL) and comparison of channel and land features. A printed circuit board (PCB) current collector is used to achieve this fuel cell configuration. 


\section{Experimental}

\subsection{Open-cathode fuel cell design}

The PEFC consisted of two printed circuit board (PCB) current collectors (anode and cathode), a membrane electrode assembly (MEA), gaskets and two end-plates. PCBs have been widely used as current collectors for fuel cells [18-20]; here the PCB geometry was 1.6 mm thick and contained a $38 \mu \mathrm{m}$ layer of copper, which was coated with a proprietary carbon-based ink for corrosion protection. The gaskets used for gas manifolds were made of silicone and were $0.4 \mathrm{~mm}$ thick, and those used as seals between the end plate and current collector were $0.15 \mathrm{~mm}$ thick. A double-serpentine flow-field geometry was used for the anode and a parallel vertical flow-field was used for the cathode. A schematic of the design is shown in Figure 1. The $1 \mathrm{~mm}$ slits in the cathode flow-field where the GDL is exposed to the atmosphere are referred to as 'channels' and the $1 \mathrm{~mm}$ wide sections of PCB material between the channels are referred to as 'lands'.

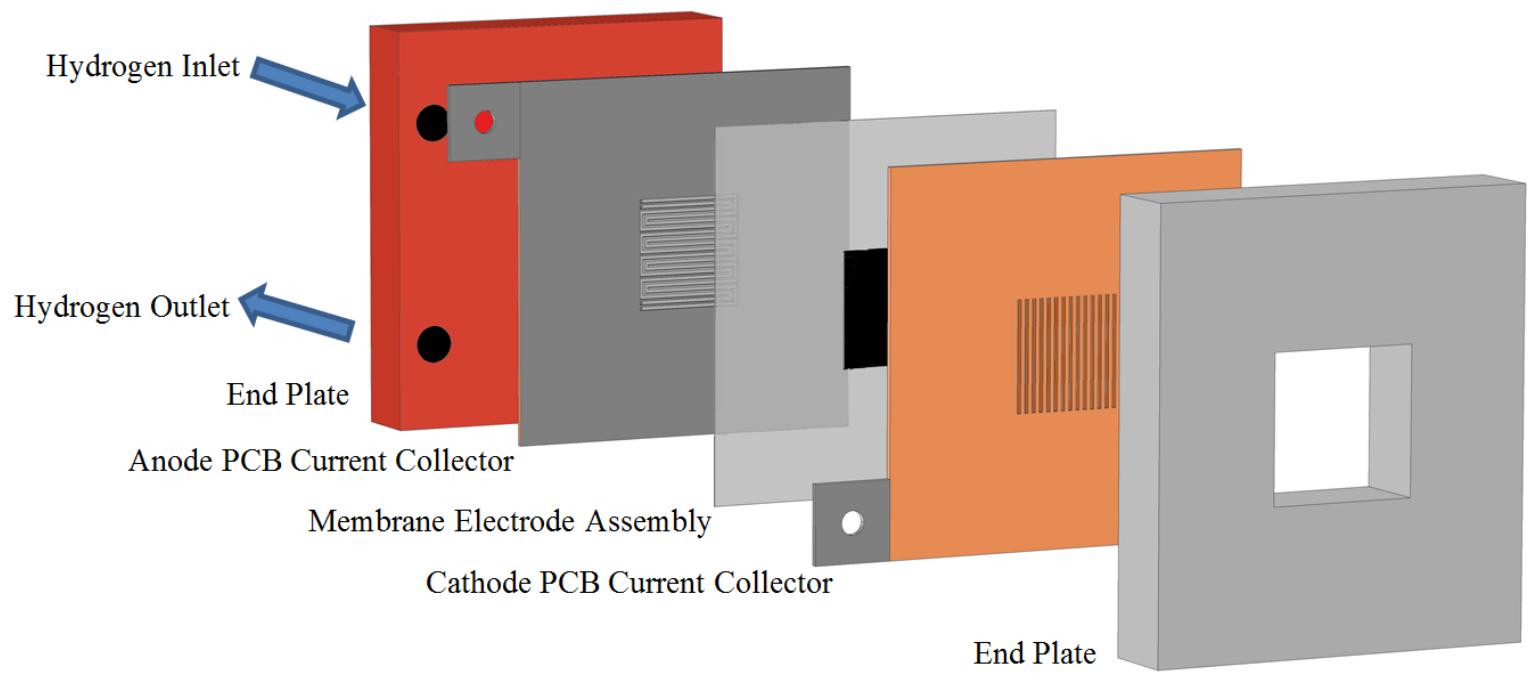

Figure 1 - Schematic of the open-cathode PEFC design. The MEA can be directly viewed through the aperture in the end-plate and the open channels in the cathode current collector. 
The cathode end-plates were made from aluminium and contained a $13 \mathrm{~cm}^{2}$ square open window for direct visualization of the flow-field. The size of this window was larger than the active area of the cell and had negligible effect on the electrochemical performance of the cell. A torque of $3.6 \mathrm{Nm}$ was applied to each of the four tie bolts to compress the cell and achieve a similar performance as achieved by Obeisun et al. in previous studies $[18,19]$.

\subsection{MEA fabrication}

The electrolyte, Nafion 117 (Fuel Cell Store, USA), was pre-treated at $80{ }^{\circ} \mathrm{C}$ in $3 \% \mathrm{H}_{2} \mathrm{O}_{2}$ (Sigma Aldrich, UK) and then $1 \mathrm{M} \mathrm{H}_{2} \mathrm{SO}_{4}$ (Sigma Aldrich, UK). The MEAs were produced in-house using the electrolyte and ELE0237 Johnson Matthey $0.4 \mathrm{mg} \mathrm{cm}^{-2}$ platinum electrodes (Johnson Matthey Fuel Cells, UK) with an active area of $9.6 \mathrm{~cm}^{2}$. The MEAs were pressed (Carver $4122 \mathrm{CE}$, USA) at $170{ }^{\circ} \mathrm{C}$ for 4 minutes with an applied pressure of $3100 \mathrm{kPa}$.

\subsection{Thermal imaging}

Thermal imaging was performed using a $640 \times 512$ focal plane array $\mathrm{InSb}$ camera (SC5000MB FLIR, UK). The camera was calibrated for the temperature range in question $\left(15-60{ }^{\circ} \mathrm{C}\right)$ with the images being recorded using commercially available software (ResearchIR, FLIR ATC, Croissy-Beaubourg, France) at 100 frames per second. ETIS was performed by fixing the location of the camera in relation to the cell and selecting identical pixels through the range of frequencies examined. The emissivity of the cathode GDL was calculated to be in excess of 0.95 over the temperature range observed during the experiments. 
Thermal images were post-processed using commercially available software to obtain temporal temperature data and lock-in images (Altair LI, FLIR ATC, Croissy-Beaubourg, France). In this study, because the stimulus is electrical current and the area of interest is the amplitude ratio, images are referred to as 'electro-thermo-ampligrams'.

\subsection{Fuel Cell Testing}

A fuel cell test station (840 Advanced Fuel Cell Test System, Scribner Associates, USA) was used to supply dry hydrogen gas to the fuel cell anode. Hydrogen (99.995\% purity, BOC plc, UK) was supplied at ambient temperature at a rate of $100 \mathrm{~mL} \mathrm{~min}^{-1}$. The cathode was open to the atmosphere.

An IviumStat potentiostat (Alvatek, UK) was used to apply single frequency current perturbations with $3 \mathrm{~mA} \mathrm{~cm} \mathrm{~cm}^{-2}$ amplitudes between $100 \mu \mathrm{Hz}$ and $1 \mathrm{~Hz}$ to the fuel cell and measure the voltage response. The current was measured with a current probe (Tektronix A622, RS Components Ltd., UK) and recorded in a data acquisition unit (USB 6363 Multifunction DAQ, National Instruments, USA) which amplified the signal to an equivalent stimulus signal within the specifications of the thermal imaging camera $(0-10 \mathrm{~V})$.

\section{Results and discussion}

In order to determine a suitable amplitude of the current perturbation and determine the linearity or response, the temperature responses to $1,2,3$, and $5 \mathrm{~mA} \mathrm{~cm} \mathrm{~cm}^{-2}$ peak amplitude current perturbations were investigated. Figure 2 shows the thermal responses in the time domain under a $0.1 \mathrm{~Hz}$ current perturbation with a $30 \mathrm{~mA} \mathrm{~cm}{ }^{-2}$ direct current (dc) offset. It

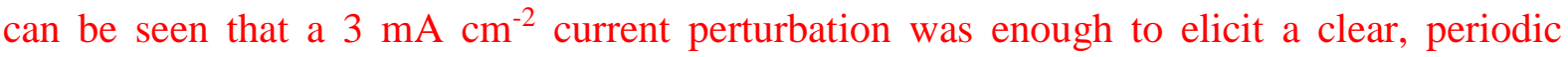


temperature response. The sinusoidal temperature response (linearity) of the temperature response at this amplitude can be observed.

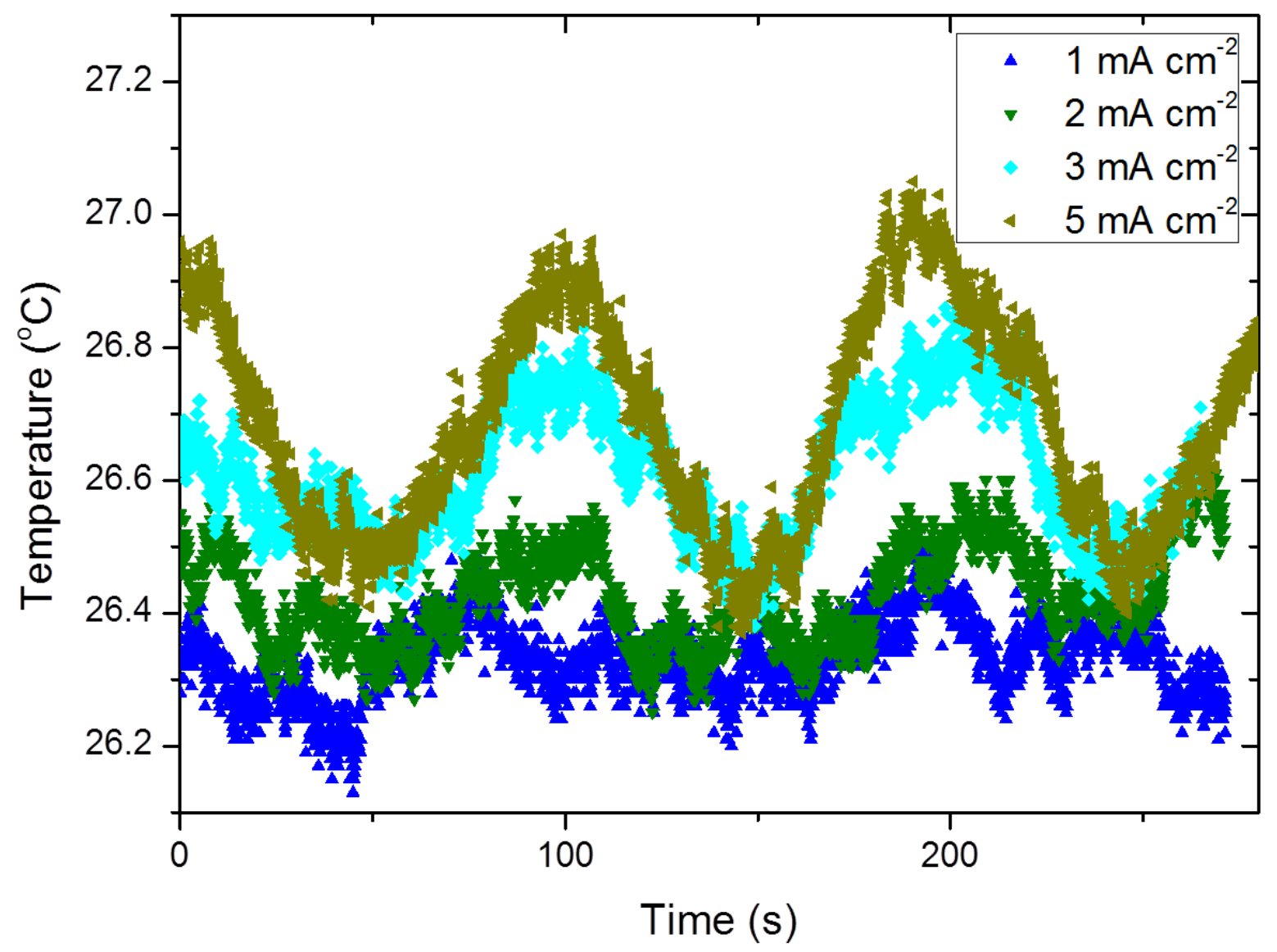

Figure 2 - Temporal temperature responses to current stimuli of 1, 2, 3 and $5 \mathrm{~mA} \mathrm{~cm}{ }^{-2}$ peak amplitude. The perturbations had a constant frequency of $0.1 \mathrm{~Hz}$ with a $30 \mathrm{~mA} \mathrm{~cm}^{-2} \mathrm{dc}$ offset. Temperatures were recorded in a region near the middle of the fuel cell cathode using a thermal imaging camera.

A $3 \mathrm{~mA} \mathrm{~cm}^{-2}$ peak amplitude current perturbation was applied to the system with a fixed 30 and $250 \mathrm{~mA} \mathrm{~cm} \mathrm{~cm}^{-2} \mathrm{dc}$ offset. A sinusoidal fit was applied to the current perturbation and temperature response in the form of Equation 1:

$i, T\left(\mathrm{~A},{ }^{\circ} \mathrm{C}\right)=A_{i_{3} T} \sin \left(2 \pi f t+B_{i, T}\right)+C_{i_{2} T}$ Equation 1 
Where $A$ is the peak amplitude of the wave, $f$ is the frequency, $t$ is the time, $B$ is the time offset, and $C$ is the current $(i)$ or temperature $(T)$ offset. An example of the current and temperature data to which Equation 1 was applied is shown in Figure 3.

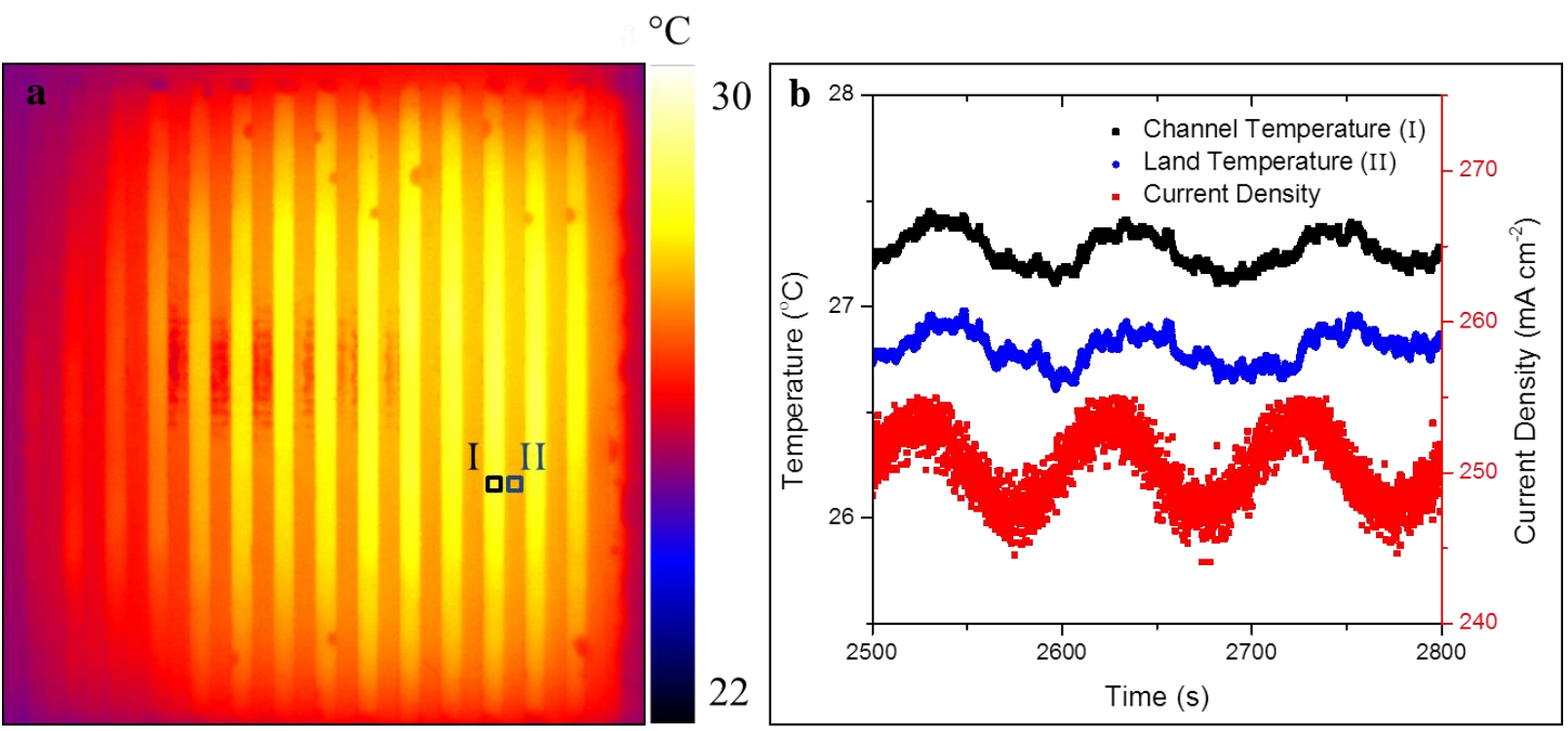

Figure 3 - Thermal image (a) depicting area of the channel (I) and of the land (II) considered. Temporal data (b) of current stimulus (red) plotted with the temperature response of the channel (black) and land (blue) acquired from thermal imaging. A fit in the form of Equation 1 was applied to the current and temperature signals in order to determine the amplitude and time offset of each signal.

Subsequently, the amplitude ratio (AR) at each frequency can be evaluated as the relative peak amplitude of the thermal response $\left(\mathrm{A}_{T}\right)$ and current perturbation $\left(\mathrm{A}_{\mathrm{i}}\right)$.

$\operatorname{AR}\left({ }^{\circ} \mathrm{C} \mathrm{A}^{-1}\right)=\frac{A_{T}}{A_{\tilde{\mathrm{i}}}}=\frac{A_{T}}{0.03 \mathrm{~A}}$ Equation 2

The phase shift is the difference in the time off-set between the temperature $\left(\mathrm{B}_{\mathrm{T}}\right)$ and the current $\left(\mathrm{B}_{\mathrm{i}}\right)$. 
$\emptyset($ degrees $)=\left(B_{T}-B_{i}\right) \frac{180}{\pi}$

Equation 3

The amplitude ratio and phase shift were plotted as a function of frequency for an area in the middle of a cathode open channel and an area in the adjacent land. The Bode plot for these measurements is shown in Figure 4.
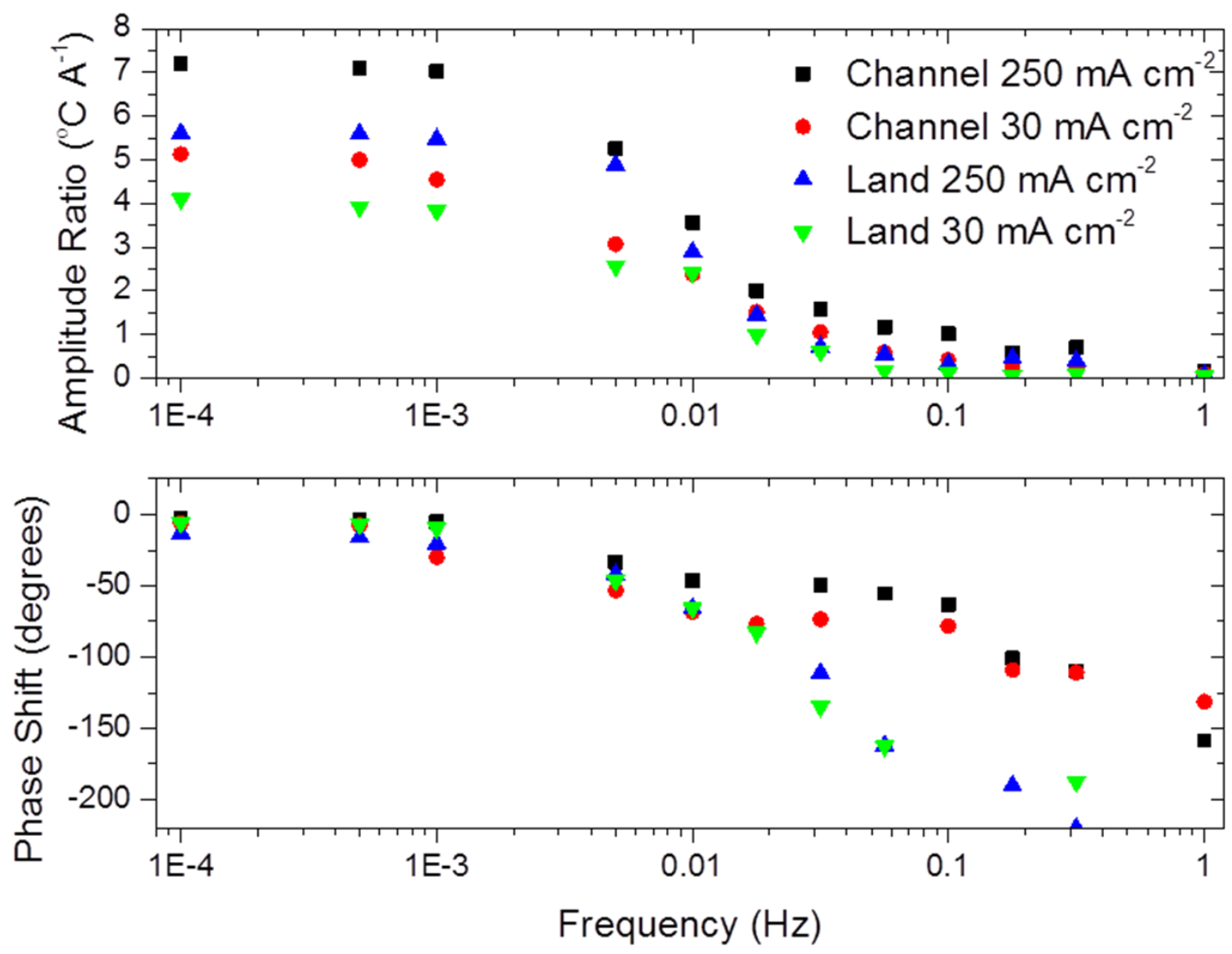

Figure 4 - ETIS Bode plots (amplitude ratio - top, and phase shift - bottom) for channel and land locations at 30 and $250 \mathrm{~mA} \mathrm{~cm}$. The plot demonstrates the relationship between the temperature response and current stimulus as a function of frequency and location. The system was perturbed with a fixed $3 \mathrm{~mA} \mathrm{~cm}^{-2}$ peak amplitude current stimulus. 
From Figure 4, it can be observed that at low frequencies (below $1 \mathrm{mHz}$ ) the magnitude of the amplitude ratio is significantly larger in the channel location than in the land location, for both direct current offset values. This is because the thermal mass of the land adds additional thermal impedance, thus damping the thermal response. Additionally, at $250 \mathrm{~mA} \mathrm{~cm}^{-2}$, there is a greater low frequency amplitude ratio than for $30 \mathrm{~mA} \mathrm{~cm}^{-2}$. Due to the fact that the amplitude of the current perturbation is fixed for both dc current densities, the higher amplitude ratio means that the differential heat generation term is more significant under the higher loading condition. Since the rate of Ohmic heat generation increases linearly with dc current, the higher amplitude ratio must be related to decreased efficiency of heat dissipation at the higher current density.

With increasing frequency, the amplitude ratios decrease and converge as the modulation wavelength moves away from the characteristic thermal diffusion length of the fuel cell features.

Below $1 \mathrm{mHz}$, the magnitude of the phase shift in the channel and land locations is near zero at both dc current densities, indicating that the system has had sufficient time to thermally equilibrate. With increasing frequency, the magnitude of the phase shift increases more rapidly for the land, due to the added thermal diffusion length of the land compared to the channel, i.e., the land moves out-of-phase with the current stimulus at a faster rate than the channel. The difference in phase shift between the channel and land at $200 \mathrm{mHz}$ is approximately 100 degrees. The phase shift profile across the spectrum between the two dc current densities does not vary significantly and thus the phase shift is not very sensitive to polarisation.

In order to investigate the spatial variation of the amplitude ratio at different dc current densities, the lock-in technique was applied to generate electro-thermo-ampligrams at two 
different frequencies, selected from the ETIS spectrum. Figure 5 compares the conventional thermograms (a, d) to the electro-thermo-ampligrams at $100 \mathrm{mHz}(\mathrm{b}, \mathrm{e})$ and $1 \mathrm{mHz}$ (c, f) for dc current densities of $30 \mathrm{~mA} \mathrm{~cm}^{-2}$ (a-c) and $250 \mathrm{~mA} \mathrm{~cm}^{-2}$ (d-f).

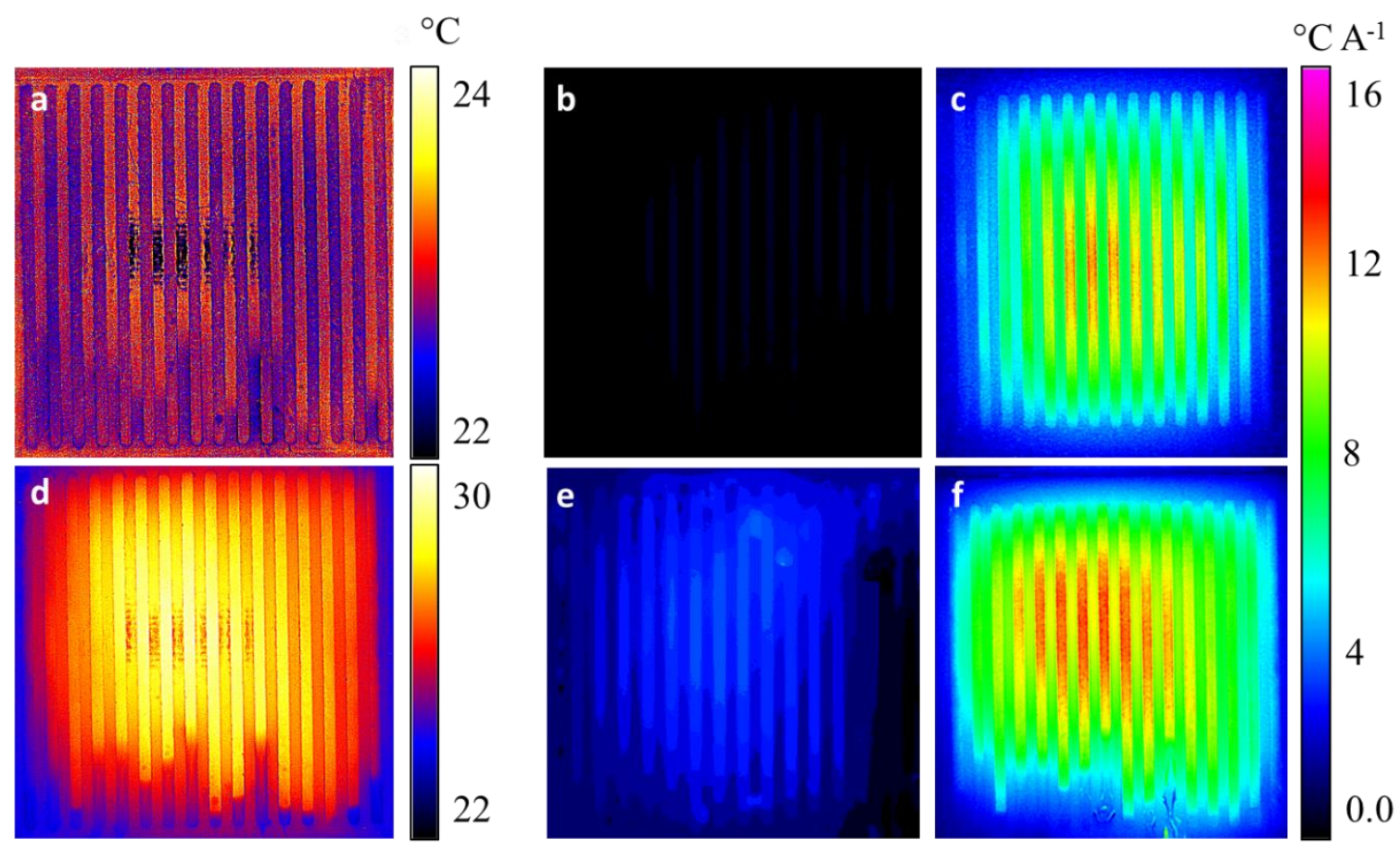

Figure 5 -Thermograms (a,d) and electro-thermo-ampligrams at $100 \mathrm{mHz}(\mathrm{b}, \mathrm{e})$ and $1 \mathrm{mHz}(\mathrm{c}, \mathrm{f})$ of a PEFC cathode at $30 \mathrm{~mA} \mathrm{~cm}{ }^{-2}$ (a-c) and $250 \mathrm{~mA} \mathrm{~cm}^{-2}$ (d-f). The system was perturbed with a fixed $3 \mathrm{~mA} \mathrm{~cm}^{-2}$ peak amplitude current stimulus.

Artefacts caused by the Narcissus Effect, i.e. the reflection of the lens on the surface of the sample [21, 22], can be observed in the centre of the thermograms - Figures 5(a) and 5(d). Additionally, the channels appear to be cooler than the lands in Figure 5(a), when in fact the channels are warmer than the lands due to generation of heat in the electrode. This is a consequence of the difference in emissivity of the two materials and is a major challenge for IR thermography in general. The application of alternating current (ac) thermography automatically corrects for differences in emissivity and the reflections do not appear in the 
electro-thermo-ampligrams (b, c, e, f). Removal of such artefacts is a major advantage of the ETIS technique.

At $100 \mathrm{mHz}$, the amplitude ratios - and consequent contrast in the images in Figure 5(b) and 5(e) - are much lower than at $1 \mathrm{mHz}$, in agreement with the manually calculated values in Figure 4. The electro-thermo-ampligrams explicitly show where heat is generated, not just the temperature distribution. As such, the dc and ac techniques are highly complementary. By definition, the electro-thermo-ampligram is sensitive to temperature changes caused by the current stimulus and insensitive to absolute temperature; so parameters that change as a consequence of the current cycle can be targeted. For example, since water generation is linked to current, there is the possibility to target its formation and removal. Water droplets are clearly discernible in the channels in the electro-thermo-ampligram in Figure 5(e), but not in the corresponding thermogram in Figure 5(d).

As water generation will change the thermal conductivity of the GDL, there is even the possibility of identifying water generated within the GDL or under lands. When comparing the bottom of the flow-field in Figures 5 (c) and 5(f), the higher current case leads to lower amplitude ratios in both the channel and the land locations. Visual inspection shows that this is correlated with water formation, acting as a barrier to heat transfer. Conversely, heat generation from pinhole formation being a non-current induced phenomenon, a hot spot due to a pin hole in the membrane will be identifiable by a thermogram, but not an electrothermo-ampligram. Further work is required to tune the technique to identify different features in fuel cells. 


\section{Conclusions}

ETIS has been applied to a PEFC for the first time to determine the frequency, polarisation, and spatial-dependence of the thermal behaviour of the fuel cell when a periodic current perturbation is applied. A greater thermal diffusive length between the source of the heat and surface of the system yields a greater phase shift and lower amplitude ratio. Based on the ETIS analysis, frequencies can be selected in order to achieve greatest image contrast or tune the technique to identify different features in the electro-thermo-ampligram. As such, DC and AC thermography are highly complementary and allow current-dependent features such as water generation to be decoupled from the absolute temperature distribution and non-currentdependant effects.

\section{Acknowledgements}

The authors would like to acknowledge the NMS Innovation R\&D Programme at NPL for supporting the work of Hinds, Engebretsen and Brett; the Sunshine Oil and Chemical Development Company Limited for supporting Obeisun and the EPSRC for funding the Electrochemical Innovation Lab's fuel cell research programme through (EP/K038656/1; EP/G060991/1; EP/J001007/1; EP/I037024/1; EP/G030995/1; EP/G04483X/1). PRS acknowledges the Royal Academy of Engineering for funding support.

\section{References}

[1] R.P. O'Hayre, Fuel Cell Fundamentals, Wiley, New Jersey, 2006.

[2] M. Mench, Fuel Cell Engines, Wiley, New Jersey, 2008.

[3] J.P. Diard, B.L. Gorrec, C. Montella, in: Bio-Logic (Ed.), Claix, France, 2013.

[4] A. Lasia, Electrochemical Impedance Spectroscopy and its Applications, in: Modern Aspects of Electrochemistry, Springer, 2002. 
[5] M. Orazem, B. Tribollet, Electrochemical Impedance Spectroscopy, Wiley, Hoboken, New Jersey, 2008.

[6] D.J.L. Brett, A.R. Kucernak, P. Aguiar, S.C. Atkins, N.P. Brandon, R. Clague, L.F. Cohen, G. Hinds, C. Kalyvas, G.J. Offer, B. Ladewig, R. Maher, A. Marquis, P. Shearing, N. Vasileiadis, V. Vesovic, Chem. Phys. Phys. Chem, 11 (2010) 2714 - 2731.

[7] J.P. Schmidt, D. Manka, D. Klotz, E. Ivers-Tiffée, Journal of Power Sources, 196 (2011) 8140-8146.

[8] E. Barsoukov, J.H. Jang, H. Lee, Journal of Power Sources, 109 (2002) 313-320.

[9] E. Barsoukov, J.R. Macdonald, Impedance Spectroscopy: Theory, Experiment, and Applications, 2nd ed., Wiley, 2005.

[10] S. Huth, O. Breitenstein, A. Huber, D. Dantz, U. Lambert, F. Altmann, Solid State Phenomena, 82-84 (2001) 741-746.

[11] O. Breitenstein, W. Warta, M. Langenkamp, Lock-in Thermography: Basics and Use for Evaluating Electronic Devices and Materials, 2 ed. ed., Springer, 2003.

[12] J.B. Robinson, E. Engebretsen, D. Finegan, J.A. Darr, G. Hinds, P.R. Shearing, D.J.L. Brett, ECS Electrochemistry Letters, In press.

[13] S. Rißland, O. Breitenstein, Solar Energy Materials and Solar Cells, 104 (2012) 121-124.

[14] S. Besold, U. Hoyer, J. Bachmann, T. Swonke, P. Schilinsky, R. Steim, C.J. Brabec, Solar Energy Materials and Solar Cells, 124 (2014) 133-137.

[15] J.P. Rakotoniaina, O. Breitenstein, M. Langenkamp, Materials Science and Engineering: B, 91-92 (2002) 481-485.

[16] Y.-K. An, J. Yang, S. Hwang, H. Sohn, Optics and Lasers in Engineering, 73 (2015) 128-136.

[17] J.B. Robinson, L.D. Brown, R. Jervis, O.O. Taiwo, T.M.M. Heenan, J. Millichamp, T.J. Mason, T.P. Neville, R. Clague, D.S. Eastwood, C. Reinhard, P.D. Lee, D.J.L. Brett, P.R. Shearing, Journal of Power Sources, 288 (2015) 473-481.

[18] O.A. Obeisun, Q. Meyer, J. Robinson, C.W. Gibbs, A.R. Kucernak, P.R. Shearing, D.J.L. Brett, International Journal of Hydrogen Energy, 39 (2014) 18326-18336.

[19] O.A. Obeisun, Q.P.-G. Meyer, J. Robinson, C. Gibbs, A.R.J. Kucernak, P.R. Shearing, D.J.L. Brett, ECS Transactions, 61 (2014) 249-258.

[20] F.A. Daniels, C. Attingre, A.R. Kucernak, D.J.L. Brett, Journal of Power Sources, 249 (2014) 247-262.

[21] M. Vollmer, L.-P. Möllmann, Infrared Thermal Imaging: Fundamentals, Research and Applications, Wiley-VCH, 2010.

[22] T.L. Williams, Thermal Imaging Cameras: Characteristics and Performance, CRC Press, Boca Raton, 2009. 